\title{
PERCURSOS FORMATIVOS DE GESTORES ESCOLARES:
}

\section{GRUPO DE REFERÊNCIA}

Renata Nascente

\begin{abstract}
Resumo
O objetivo deste artigo é apresentar e discutir o percurso formativo trilhado por um grupo de educadores no contexto de uma formação oferecida pela Secretaria da Educação do Estado de São Paulo - SEE/SP por meio dos Grupos de Referência - GR a diretores de escola, supervisores de ensino e professores coordenadores de escolas de ensinos fundamental e médio, em um período de dois anos e meio, de julho de 2011 a outubro de 2013. Essa problematização dividiu-se em dois questionamentos: como se caracterizaram os percursos formativos dos gestores escolares participantes do GR investigado? Houve algum tipo de articulação entre essa formação específica e suas respectivas práticas educacionais? Esses questionamentos foram tematizados com base em dois princípios fundamentais da gestão democrática da educação e da escola: a autonomia e a participação. Na primeira parte do artigo, caracterizamos a formação em estudo e apresentamos nossa metodologia de pesquisa. Na seguinte, que compreende três etapas da formação em estudo, 2011, 2012 e 2013, descrevemos e problematizamos os percursos formativos dos gestores participantes. Na terceira, analisamos e discutimos a formação dos gestores no GR à luz de nossos referenciais teóricos. Nas considerações finais explicitamos nossas perspectivas em relação a essa formação com foco nas possíveis articulações entre teorias e práticas e no desenvolvimento das concepções de autonomia e participação dos gestores que dela participaram.
\end{abstract}

Palavras-chave: Grupo de Referência; Formação de Educadores; Gestão Democrática.

\section{SCHOOL MANAGERS DEVELOPMENT PATHS: \\ REFERENCE GROUP}

\begin{abstract}
This article aims at presenting and discussing the development path taken by an educators group in the context of a course offered by São Paulo State Education Bureau through the Reference Groups to state public school principals, coordinators and supervisors, during two years and a half, from June 2011 until October 2013. The problem was divided into two basic questions: which were the group development process main features? Was there any sort of specific articulation between the course and the educational practices of the group? These questions were problematized based on two democratic management fundamental principles: autonomy and participation. The article is organized in three parts: in the first one, the course is characterized and the investigation methodology is presented. In the following one, which comprises three phases of the course in study, 2011, 2012 e 2013, the group development paths are discussed. In the third part we analyze and discuss the development of the educators under the light of our theoretical framework. In our final considerations we explicit our views regarding the course, focusing the possible articulations between theorizations and school practices and the development of autonomy and participation conceptions within the group.
\end{abstract}

Key-words: Reference Group; Development of Educators; Democratic Management. 


\section{Introdução}

A democratização e a consequente universalização da educação básica no Brasil, referendadas pela LDBN - Lei 9394/1996 (BRASIL, 1996) e reafirmadas em diversos documentos, normativas e diretrizes oficiais, inclusive no PNE - Plano Nacional de Educação, aprovado em 2014 (BRASIL, 2014), têm propiciado o surgimento de novos paradigmas de gestão escolar. A partir da década de 1990, novas demandas foram sendo apresentadas às escolas públicas, que se viram na contingência de acolher todas as crianças e jovens de seis a 18 anos de idade, que trouxeram consigo uma imensa diversidade nos campos econômico, social, étnico, cultural, de gênero e de necessidades especiais. Nesse novo cenário, a figura do diretor como líder único na escola, em uma perspectiva patrimonialista, individualmente responsável tanto pelas atividades meio como pelas atividades fim, parece estar gradualmente se esvaindo.

A reorganização dos sistemas de ensino e das escolas de educação básica com base na gestão democrática e na oferta de uma educação de qualidade social tem ocasionado câmbios significativos relativos à formação, ao trabalho, enfim, à identidade dos diretores de escola. Em outras palavras, esses educadores têm sido instados a abandonar, ainda que isso venha acontecendo muito gradualmente, o isolamento e a posição de liderança que historicamente lhe eram atribuídos, para compor, juntamente com outros educadores, equipes gestoras. Por outro lado, os sistemas de ensino - estados e municípios, têm desenvolvido políticas educacionais caracteristicamente gerencialistas, fundamentadas nos princípios da Nova Gestão Pública (AFONSO, 2003), com ênfase na responsabilização dos diretores não só pelos resultados aferidos pelas avaliações externas, mas por toda a vida escolar, especialmente nos âmbitos legais e orçamentários, sem uma contrapartida em termos de autonomia de gestão.

Levando em consideração essa reconfiguração da gestão escolar é que se estabelece a relevância deste artigo. É fundamental compreender os processos formativos pelos quais têm passado nossos gestores escolares, nas faculdades/ universidades e por meio de cursos e outros processos formativos ofertados pelos próprios sistemas de ensino nos quais estão inseridos, pois essas formações parecem ser um dos fundamentos do trabalho e da identidade desses gestores.

Importa esclarecer que nosso entendimento de formação é o de Imbernón (2005; 2009), isto é, a formação do educador é permanente, não havendo segmentação entre 
formação inicial, nos cursos de licenciatura, e continuada. Em coerência com esse estudioso, pensamos ser a formação do educador um processo contínuo, que começa em sua família, passa pela escolarização básica e vai se construindo ao longo de sua vida.

Nesse sentido, também adotamos o conceito de profissionalidade docente de Contreras (2002), concebendo a profissionalidade dos gestores escolares como resultado dinâmico e flexível da articulação entre formação e trabalho, em uma perspectiva crítica e reflexiva, referenciada na busca pela autonomia e pelo compromisso com a comunidade, aliando competência profissional e responsabilidade social.

Com o intuito de ampliar nossa compreensão sobre processos formativos de gestores escolares é que se objetiva este artigo, isto é, pretendemos apresentar e tematizar o percurso formativo trilhado por um grupo de educadores no contexto de uma formação oferecida pela Secretaria da Educação do Estado de São Paulo - SEE/SP por meio dos Grupos de Referência - GR a diretores de escola, supervisores de ensino e professores coordenadores de escolas de ensinos fundamental e médio, os chamados trios gestores na rede estadual, em um período de dois anos e meio, de julho de 2011 a outubro de 2013. Essa problematização divide-se em dois questionamentos: como se caracterizaram os percursos formativos dos gestores escolares participantes do GR investigado? Houve algum tipo de articulação entre essa formação específica e suas respectivas práticas educacionais?

Esses questionamentos são discutidos com base nos dois princípios fundamentais da gestão democrática: a autonomia, que na escola "refere-se à liberdade, dentro dos limites impostos pela legislação, que ela tem para estabelecer e executar o projeto de educação que lhe pareça o melhor" (RISCAL, 2009, p.53); e a participação que pressupõe "uma forma coletiva de tomada de decisões" (...) advogando "(...) que cada membro da equipe assuma sua parte no trabalho, admitindo a coordenação e a avaliação sistemática da operacionalização das deliberações" (LIBÂNEO; OLIVEIRA; TOSCHI, 2009, p. $325)$.

Essa discussão é fundamental na medida em que os conceitos de autonomia e de participação são anunciados como norteadores da formação em estudo e, principalmente, porque deles não se pode abrir mão, não só pelas demandas da sociedade por uma escola mais democrática, ou pelo próprio ordenamento legal vigente que os estabelece para escolas e sistemas, mas por uma questão de sobrevivência da escola como instituição 
social. Em outras palavras, pelo fortalecimento da autonomia e da participação dos segmentos no exercício da democracia, praticado nos diversos colegiados, é que escolas e sistemas poderão encontrar encaminhamentos para alguns seus problemas mais graves, tais como baixos índices de aprendizagem dos estudantes, acolhimento à diversidade e violência e indisciplina na escola.

Este artigo está organizado em três partes. Na primeira delas caracterizamos a formação em estudo e apresentamos nossa metodologia de pesquisa. Na seguinte, que compreende três etapas da formação em estudo, 2011, 2012 e 2013, descrevemos e problematizamos os percursos formativos dos gestores participantes. Em seguida, na análise e discussão da formação dos gestores no GR, explicitamos nossos posicionamentos em relação a essa formação com foco nas possíveis articulações entre teorias e práticas e no desenvolvimento das concepções de autonomia e participação dos gestores que dela participaram.

\section{Caracterização da formação e metodologia de pesquisa}

O lócus dos percursos formativos a serem discutidos neste artigo foi um dos Grupos de Referência - GR. Esses Grupos foram reunidos pela Secretaria Estadual da Educação do Estado de São Paulo - SEE/SP, nas 91 Diretorias de Ensino - DE, tendo sua organização explicitada no Plano de Formação Continuada de Professores e Gestores, lançado em junho de 2011 (SÃO PAULO, 2011).

Os encontros realizavam-se nos Núcleos de Formação, que eram compostos por um conjunto de DE, de duas a sete, cuja constituição foi orientada pelo critério da proximidade geográfica e pelo número de escolas que cada uma abrangia. Cada um dos GR deveria composto de 25 a 30 membros, supervisores de ensino, diretores de escola, professores coordenadores, integrantes da CENP $^{1}$ e um consultor, preferencialmente docente de uma universidade pública. Essa formação se estendeu de julho de 2011 a outubro de 2013.

Para compreender os percursos formativos dos gestores, sem termos uma hipótese pré-estabelecida, foi utilizada uma abordagem metodológica qualitativa e exploratória de pesquisa em educação (BODGAN; BIKLEN, 2010). Os procedimentos/ instrumentos de pesquisa foram observações realizadas durante todos os encontros e análise documental (GIL, 2002) dos Planos de Formação Continuada de Professores e Gestores (SÃO PAULO, 2011; 2012). 


\section{Percursos formativos no Grupo de Referência}

Esta seção se subdivide em três etapas da formação no GR, nos anos de 2011, 2012 e 2013 em razão de que em cada um desses períodos houve mudanças e permanências significativas no processo formativo dos gestores. Assim, optamos por essa divisão por ser facilitadora da compreensão desse processo.

\subsection{A experiência do novo: 2011}

Em julho de 2011, foi solicitado às DE que selecionassem os participantes para seus respectivos GR, que deveriam ser preferencialmente gestores experientes, que tivessem cursado alguma pós-graduação e demonstrassem compromisso profissional (SÃO PAULO, 2011, p.09), objetivando estruturar em parceria com alguma universidade pública uma formação que subsidiasse outros processos formativos a serem desenvolvidos em cada uma das DE e em suas respectivas escolas.

O primeiro encontro formativo ocorreu em um clima misto de curiosidade e desconfiança. Apesar da publicação do Plano (São Paulo, 2011), com um mês de antecedência em relação a esse encontro, a maioria dos participantes não havia se apropriado dele. Eles pareciam ter uma percepção de que trataria de algo de diferente em relação às outras formações oferecidas a gestores pela SEE, que eles percebiam como fundamentalmente centralizadas. Essa novidade gerou também desconfiança, porque nas formações centralizadas se sabia com antecedência os temas que seriam abordados, os objetivos a serem alcançados, e qual setor ou pessoal da SEE/SP se responsabilizaria pelo trabalho. Todos esses dados, que normalmente indicavam o que se poderia esperar de uma formação, estavam ausentes no GR e geraram questionamentos sobre quem seriam os formadores, quais seriam as temáticas, e principalmente, se seriam fornecidos subsídios para ações a serem desenvolvidas nas escolas.

O fato é que o primeiro encontro contou com a participação de supervisores, diretores e professores coordenadores de cada uma das DE do Núcleo 02 como havia sido previsto. Não houve, entretanto, a presença do assessor universitário, aparentemente por questões burocráticas da SEE/SP. Isso se constituiu em uma decepção para os 
participantes. Eles expressaram claramente que a parceria com a universidade seria o diferencial do GR no qual depositavam significativa expectativa. Eles tinham a esperança que essa parceira com a universidade traria novos elementos, principalmente referenciais teóricos, importantes para uma compreensão mais apurada de suas práticas e possíveis aprimoramentos.

Como não havia o assessor universitário, as expectativas se voltaram para as duas formadoras da SEE/SP que vieram de São Paulo para coordenar o primeiro encontro. Ocorreu que essas formadoras não tinham conhecimento significativamente maior sobre GR do que os gestores participantes. Uma análise mais detida das observações do primeiro encontro revela que havia uma agenda predefinida para ele, mas não uma pauta estruturada como os participantes esperavam. O objetivo do encontro se constituía em um levantamento das suas expectativas em relação a sua formação pelo GR e também das formações que estavam em curso nas DE, assim como dos seus possíveis resultados.

Inicialmente, as representantes da CENP esclareceram que os participantes selecionados foram aqueles considerados em suas próprias DE como potenciais formadores e que objetivo fundamental da formação era o aprimoramento da gestão escolar. Elas também enfatizaram que não haveria uma hierarquia no grupo, ou influência da SEE/SP, todas as decisões sobre a formação deveriam ser tomadas coletivamente, pelos próprios participantes. Estes manifestaram insegurança diante dessa suposta autonomia outorgada ao grupo, principalmente por que o Plano publicado (São Paulo, 2011, p.04) estabelecia algumas regras básicas, entre as quais se destacou o trabalho referenciado pela pesquisa-ação, na perspectiva de Pimenta (2005), que tinha seus princípios explicitados, mas não explicava quais os procedimentos/ instrumentos deveriam ser seguidos/ utilizados.

Diante da falta de subsídios teóricos sobre a pesquisa-ação e também do assessor universitário, a questão da metodologia da formação no GR passou a ser uma preocupação constante do grupo, sentindo-se perdido e até certo ponto desamparado em relação a esse processo. Corroborou para esse quadro o fato de que nos dois primeiros encontros realizados em 2011 as formadoras da CENP não terem trazido nenhum texto, ou mesmo informação sobre a pesquisa-ação que ultrapassasse a que se apresentava no plano.

Cabe aqui uma discussão sobre a autonomia outorgada ao GR pela SEE/SP. Anunciada no Plano (São Paulo, 2011), ela não foi percebida naquele momento pelos 
gestores como uma oportunidade de construir uma formação significativa, baseada em suas próprias demandas, contextualizada em suas realidades profissionais, mas como uma formação improvisada pela CENP, órgão responsável por ela. O espaço, ainda que limitado, criado para a formação, foi entendido como uma espécie de vácuo, de falta de repertório por parte da SEE/SP, talvez uma boa ideia, prematuramente lançada na rede estadual. Essa percepção de improvisação foi criando, no segundo e no terceiro encontros de 2011 um clima de descrença e de decepção.

Portanto, apesar de alguma autonomia ter sido outorgada pela SEE/SP, o grupo parecia não querer tomar as rédeas de sua própria formação, desejando que alguém da CENP trouxesse uma formação pronta, que pudesse ser aproveitada de forma imediata na gestão das escolas e nas DE. Por um lado, a SEE/SP deu algum espaço para que se construísse uma formação relativamente autônoma, o que no discurso dos participantes era por eles ansiado, por outro, a descontinuidade e inconsistência das ações da CENP em relação à formação e o fato dos gestores envolvidos estarem acostumados a formações quase que completamente diretivas pode ter dificultado a construção de uma formação relativamente autônoma por parte deles.

Apesar dessa situação, é possível vislumbrar certo nível de articulação entre teoria e prática nas experiências formativas no GR. Essa articulação nos pareceu ter se constituído nos dois sentidos, formação influenciando práticas e vice-versa. As evidências dessa mútua influência emergiram nas falas dos participantes em vários momentos dos dois primeiros encontros. Elas surgiram fundamentalmente no contexto de três tópicos: as expectativas do grupo em relação ao GR; as reflexões sobre essa experiência; e as ações que poderiam dela advir. Apresentamos algumas evidências dessa articulação no quadro abaixo. Houve um agrupamento dos argumentos individuais por critérios de semelhança e de sentido. Esse procedimento foi utilizado com objetivo de sintetizar essas evidências.

\section{TABELA 01: INFLUÊNCIAS RECÍPROCAS ENTRE FORMAÇÃO E PRÁTICAS}

\begin{tabular}{|c|l|}
\hline INFLUÊNCIAS & EXPECTATIVAS, REFLEXÕES E AÇÕES \\
\hline Formação & $\bullet \begin{array}{l}\text { Apropriação de aportes teóricos para subsidiar a elaboração } \\
\text { de planos escolares. }\end{array}$ \\
Práticas & $\begin{array}{l}\text { União do trio gestor para formação de equipe de trabalho } \\
\text { nas escolas. } \\
\text { Necessidade de trabalho coletivo a ser revertido na } \\
\text { aprendizagem dos alunos. }\end{array}$ \\
\hline
\end{tabular}




\begin{tabular}{|l|l|}
\hline & $\bullet \begin{array}{l}\text { Identificação das características das formações em curso } \\
\text { da SEE/SP antes do GR. }\end{array}$ \\
& $\begin{array}{l}\text { Elaboração de plano de ação baseado no tripé: formação, } \\
\text { material e fazer pedagógico. }\end{array}$ \\
& $\begin{array}{l}\text { Acompanhamento da equipe gestora para refletir sobre e } \\
\text { aprimorar as rotinas escolares. Organização de grupos de } \\
\text { professores para estudos e preparação de aulas. }\end{array}$ \\
\hline Práticas & $\begin{array}{l}\text { Necessidade de aprimoramento profissional dos professores } \\
\text { e de compreender melhor o perfil e a função do diretor. }\end{array}$ \\
\hline & $\begin{array}{l}\text { Levantamento das problemáticas centrais: integração entre } \\
\text { escola e comunidade, formação docente e dificuldades de } \\
\text { aprendizagem. } \\
\text { Fção focada nas escolas com baixos índices de rendimento } \\
\text { nas avaliações externas. }\end{array}$ \\
\hline
\end{tabular}

Fonte: Elaboração própria.

Ao analisar o quadro percebemos que algumas das propostas de formação contidas no Plano (São Paulo, 2011) foram se concretizando durante os dois primeiros encontros, ainda que de forma incipiente. Diferentemente de outras formações oferecidas pela SEE/SP, foram oferecidas ao grupo oportunidades de trazerem algumas problemáticas vivenciadas nas escolas para serem estudadas e refletidas. Consideramos assim, que, algumas das expectativas, reflexões e ações apresentadas acima, poderiam ter sido tematizadas pelos participantes, à luz dos referenciais teóricos pelos quais manifestaram interesse em apropriarem-se.

Essas ponderações nos levam a crer que os trabalhos iniciais do GR já estavam propiciando um nível maior de articulação entre formação e práticas do que os gestores estavam acostumados a vivenciar em outras formações oferecidas pela SEE/SP. Além disso, há indícios de que essas experiências formativas iniciais do grupo podem ter funcionado como catalizadoras de expectativas, reflexões e até mesmo de ações em relação à gestão democrática, no que se refere à elevação dos níveis de autonomia e participação das equipes escolares. Por isso reunimos alguns argumentos apresentados pelos participantes nesse campo, sintetizados e organizados à semelhança do Quadro 02.

TABELA 02: EVIDÊNCIAS - AUTONOMIA E PARTICIPAÇÃO

\begin{tabular}{|l|l|}
\hline EVIDENCIAS & \multicolumn{1}{|c|}{ EXPECTATIVAS, REFLEXÕES E AÇÕES } \\
\hline AUTONOMIA & $\begin{array}{l}\text { Constituição do GR como referência no que se refere a sua } \\
\text { gestão: elaboração própria de diagnóstico e plano de } \\
\text { trabalho. }\end{array}$ \\
$\begin{array}{l}\text { Trabalho livre, sem censura, oportunizando liberdade e } \\
\text { democracia. }\end{array}$ \\
\hline
\end{tabular}




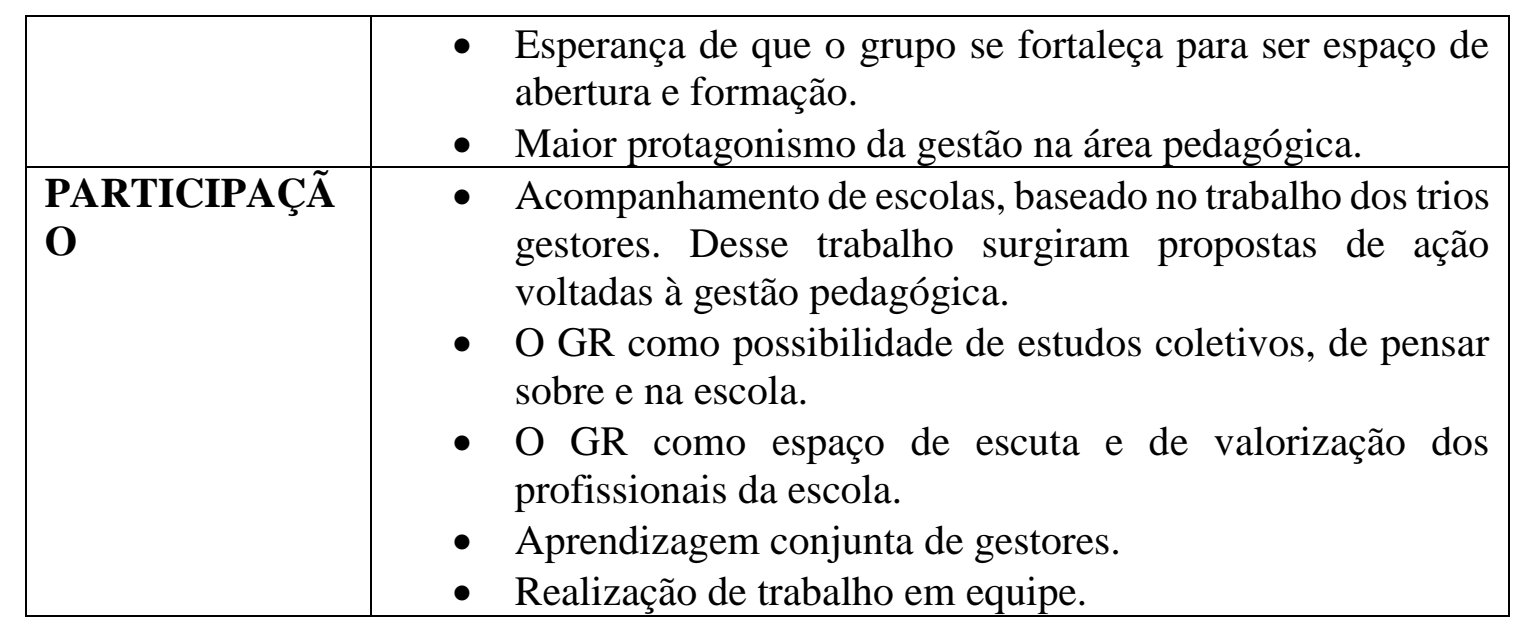

Fonte: Elaboração própria.

Destacam-se no quadro acima as manifestações dos participantes da ânsia por autonomia na construção da experiência formativa da qual estavam tomando parte. $\mathrm{O}$ trabalho livre, sem censura, norteado pela democracia aparentemente se constituiu na própria qualificação do grupo como de Referência. Portanto, caberia ao grupo diagnosticar realidades e elaborar planos de trabalho, que serviriam tanto à formação em si como também como uma forma de incentivar um maior protagonismo das equipes gestoras na gestão pedagógica.

Em relação à participação, entendemos que a percepção do grupo era a de que as experiências formativas no GR deveriam ser intrinsecamente coletivas, baseadas na escuta e na valorização dos profissionais da escola, na busca de mudanças de posturas e ideias e do fortalecimento do trabalho em equipe.

Portanto, podemos afirmar que não só grupo demonstrou potencial para gerir a própria formação e para articular aprendizagens teóricas e práticas, como também disposição para construir experiências formativas baseadas na autonomia e na participação, o que, pressupomos, deveria refletir-se nas suas práticas gestoras em suas escolas e DE.

\subsection{Por uma identidade própria: 2012}

Em março de 2012 foi lançado o Plano de Formação Continuada de Gestores 2012 (SÃO PAULO, 2012) baseado em um estudo da CENP sobre as propostas, necessidades e dados coletados nos encontros dos GR em 2011, bem como nas avaliações internas e externas à SEE/SP. Os eixos deveriam continuar sendo os mesmos desenvolvidos em 2011: gestão escolar, gestão do currículo e formação continuada em 
serviço, assim como a metodologia: a pesquisa-ação. É interessante destacar que apesar da aparente continuidade, o novo plano direcionava os trabalhos dos GR nos núcleos de formação “(...) com especial atendimento e acompanhamento dos gestores das Escolas Prioritárias e de Ensino Médio Integral, respeitando-se as especificidades de cada uma" (SÃO PAULO, 2012, p. 03).

Persiste, como podemos observar, a relatividade da autonomia outorgada pela SEE/SP aos GR, pois quando aquela percebia uma necessidade formativa em relação a alguma de suas políticas públicas, direcionava os trabalhos dos GR no sentido de dar suporte a elas. Aparentemente, os GR deveriam senão abandonar, ao menos suspender seus planos de trabalho para atender as demandas da secretaria.

A análise dos objetivos gerais e específicos dos GR em 2012 (SÃO PAULO, 2012) confirma ainda a dicotomia entre o cumprimento de políticas educacionais elaboradas pela secretaria, inclusive alimentando-as com dados das escolas que pudessem contribuir com essas elaborações, e a formação dos gestores envolvidos, de acordo com as demandas de cada GR.

Para tentar entender como a agenda estabelecida pela SEE/SP para os GR em 2012 foi compreendida pelo GR foco deste estudo, fizemos uma leitura das observações dos cinco encontros formativos realizados naquele ano. Um dado interessante refere-se ao fato de que em seu segundo ano de atividades o grupo não expressava mais as suas expectativas com tanta frequência como no ano anterior, prevalecendo à busca por uma identidade, por uma definição do que o grupo era ou deveria ser, de quais seriam seus possíveis cursos de ação. Além disso, o grupo pareceu motivado a estudar, principalmente os temas relativos à gestão democrática da escola.

A seguir apresentamos os dados relativos aos encontros formativos do GR Núcleo 02 em 2012. Eles foram organizados em três categorias: reflexões, ações e proposições. Como é esperado em uma pesquisa qualitativa e exploratória, cada agrupamento de dados é organizado de acordo com as categorias que emergem das fontes, no caso do quadro a seguir, os registros das observações. Esclarecemos ainda que os itens apresentados constituem-se em uma síntese das narrativas anotadas e que algumas expressões utilizadas pelos participantes aparecem entre aspas.

TABELA 03: reflexões, ações e proposições nos cinco encontros de 2012

\begin{tabular}{|l|l|l|}
\hline REFLEXÕES & AÇÕES & PROPOSIÇÕES \\
\hline
\end{tabular}


- GR deve continuar, pois tem se constituído em uma política relativamente horizontal e consistente da secretaria.

- O termo articulação está esvaziado, é vago, cada um tem uma ideia, é subjetivo, não se sabe bem o que a secretaria quer do GR.

- Tudo o que foi realizado no ano passado foi "jogado na máquina de lavar roupas".

- Desde seu início o GR tem contribuído para as práticas de ensino, criando possibilidades de reflexão, de aprendizagem de negociações, de sugestões.

- Tem sido possível a apropriação de algumas concepções de autonomia, participação e gestão democrática.

- A importância do registro das ações e formações desenvolvidas nas escolas e nas DE tem sido resgatada pelo GR.

- O GR propicia a horizontalidade de relações e o protagonismo das escolas.

- A relevância da participação de estudantes nos diversos colegiados escolares, o que ainda encontra resistência entre docentes nas equipes escolares.
- Discussões em

ATPC de estudos previamente realizados nos GR.

- Retomada para (re) construção do plano de trabalho do GR.

- $\quad(\mathrm{Re})$ elaboração dos planos de ação de cada diretoria, com ênfase nas relações entre teoria e prática e de acordo com alguns princípios da pesquisa-ação.

- Socialização de "boas" práticas gestoras entre as diretoras participantes.

- Incentivos a estudantes e docentes para participarem mais ativamente dos conselhos escolares e grêmios estudantis.

- Organização de encontros com gestores e professores coordenadores para discutir avaliação, pesquisa-ação e "a escola que tínhamos, temos e queremos".

- Realização de trabalhos específicos com equipes gestoras das escolas com baixo
- Mudanças na gestão escolar por meio de mudanças conceituais.

- O grupo deve dar continuidade às atividades do ano passado e da função formadora, além de encontrar um foco específico de trabalho no GR.

- A formadora da secretaria propôs a apresentação das ações do GR nas DE e que O GR deve ser o articular de todas as formações de professores e gestores em curso nas DE.

- Ampliação dos trabalhos do GR para que todas as escolas (das quatro diretorias) fossem envolvidas. 


\begin{tabular}{|l|l|l|}
\hline - $\begin{array}{l}\text { Há um relacionamento } \\
\text { intrínseco entre } \\
\text { avaliação (em suas } \\
\text { diversas concepções), o } \\
\text { conselho de classe e }\end{array}$ & $\begin{array}{l}\text { rendimento nas } \\
\text { avaliações externas. }\end{array}$ & \\
participação. & & \\
- Possibilidade de & & \\
desmistificação de & & \\
alguns mitos/ideias que & & \\
se cristalizam na & & \\
escola: "democracia & & \\
como ação entre & & \\
amigos"; e que existiria & & \\
em alguns ambientes & & \\
escolares um "pacto & & \\
pela reprovação". & & \\
\hline
\end{tabular}

Fonte: elaboração própria.

A leitura desses excertos das observações evidencia que o início dos trabalhos do GR em 2012 não foi nada fácil, pois não havia, como anunciado no Plano (São Paulo, 2012) um clima de (re) construção dos trabalhos das diretorias envolvidas e sim um sentimento misto de desconcerto e desestruturação, o que é bem traduzido pela expressão de que o que havia sido realizado e acordado no ano anterior tinha sido jogado na "máquina de lavar roupa".

Destacou-se nos encontros de 2012 o fato que em dois deles houve a presença e a ativa participação de dois professores universitários. Uma professora, juntamente com seu aluno de pós-graduação trabalhou os temas da autonomia e da participação com base no texto de Barroso (1996). Em um encontro posterior, outro professor e aluno, também pós-graduando, estudaram e discutiram a gestão democrática da escola com base no trabalho de Marques (2008). Esses colaboradores desenvolveram essas atividades voluntariamente, a convite de membros do GR Núcleo 02 e não da SEE e/ou de sua formadora. O grupo manifestou assim, motivação para estudar temas e concepções que considerou fundamentais para o desenvolvimento da gestão escolar, além de capacidade de estabelecer objetivos de suas próprias formações, buscando leituras e assessoria para isso independentemente da SEE/SP.

Percebemos assim, que de 2011 para 2012 os membros do GR foram saindo do campo das expectativas e avançando no campo das reflexões baseadas em estudos, debates, problematizações e compartilhamento de experiências. As ações desenvolvidas tiveram dois focos: sua formação em si, passos para direcionamentos e aprimoramentos, e a formação de educadores nas suas respectivas DE e escolas. O GR tornou-se também 
mais propositivo, isto é, algumas ideias de como deveria ser a própria formação e como ela deveria se desdobrar nas escolas começaram a ser aventadas. Interessante notar como essas propostas pareciam articular os estudos e discussões que vinham realizando e suas ações nas escolas.

O foco da secretaria também foi modificado em 2012 em relação a 2011. Dois encontros centralizados, com todos os GR, foram realizados em São Paulo. Os temas desses encontros, compostos de palestras de professores de universidades públicas estaduais, das áreas de gestão escolar e de políticas publicas, foram: gestão democrática, participação, autonomia e dialogicidade.

A realização dos encontros centralizados, as temáticas neles desenvolvidas e a postura da formadora do GR foco deste estudo revelam que a CEGB foi gradativamente enfatizando a importância de uma formação dentro dos princípios da gestão democrática, da autonomia e da participação, ao menos nominalmente. Por outro lado, vai havendo um paulatino desinvestimento no GR como articulador desse processo e um investimento em seu papel de executor de tarefas, tais como zelar pelo aprimoramento dos conselhos de classe e ano, levantar necessidades/demandas das escolas em função do desempenho de estudantes, combater o absenteísmo docente e algumas outras.

No final do quinto e último encontro de 2012, foi colocada a seguinte questão para os gestores: em que esse trabalho no GR tem contribuído com o trabalho realizado nas DE e nas escolas? Eles responderam que o trabalho coletivo desenvolvido no grupo estava embasando o trabalho de cada um deles e que os estudos no grupo eram fundamentais para a reinvenção de práticas gestoras contextualizadas na realidade atual. Além disso, eles reconheceram no grupo condições de estabelecer articulações entre teorias e práticas, e que de alguma maneira eles estavam sendo ouvidos pela SEE/SP. Alguns gestores consideraram ainda que formação no GR foi conduzida pela secretaria, principalmente no que se referiu às temáticas propostas para serem estudadas pelo grupo.

\subsection{O desinvestimento: 2013}

A característica mais marcante da formação em 2013 foi o gradativo desinvestimento da secretaria no GR, o que se evidencia pelo fato de não ter havido nenhum encontro centralizado naquele ano e também no fato de que o primeiro encontro formativo do GR ocorreu somente em maio. Logo de início foi esclarecido aos gestores participantes que o grupo deveria se conformar em fazer o que seria possível e desejável 
de acordo com as instruções da secretaria, notadamente gerencialistas, em relação à gestão das escolas da rede estadual.

Ficou patente naquele primeiro encontro de 2013 que a SEE já não acreditava no papel do GR como organizador das formações nas DE e que outros programas de formação centralizados estavam sendo priorizados naquele momento. Esse fato evidencia uma das possíveis causas da não efetividade de algumas formações oferecidas pela SEE a docentes e gestores, qual seja a falta de consistência dessas formações, elas parecem não serem planejadas para serem implantadas, desenvolvidas, avaliadas $\mathrm{e}$ redimensionadas, trajetória essencial para que se pudessem trazer possíveis benefícios às escolas e suas equipes.

Mesmo diante desse quadro não muito animador, ficou decidido pelo grupo no primeiro encontro que aquele GR buscaria em 2013 caminhos para desenvolver sua autoformação.

No segundo encontro de 2013 os gestores propuseram um papel para o GR, que seria o de coletar experiências exitosas e compartilhá-las no grupo, para que cada um pudesse levar para suas escolas, como referências e não como modelos. Essa colocação revelou certa maturidade do grupo naquele momento. Por outro lado, nos parece que faltou nessa reflexão conectar esses aspectos práticos, fundamentais nesse tipo de formação, com o embasamento teórico, também indispensável. Em outras palavras, os participantes poderiam estar ainda muito presos as suas práticas cotidianas.

Essa aparente lacuna vai gradativamente sendo de alguma forma trabalhada no decorrer do encontro, que também foi dedicado à compreensão das diferenças conceituais entre centralização, descentralização e desconcentração. Como não poderia deixar de ser, em uma discussão como essa o tema da autonomia foi revisitado e rediscutido. Finalmente foram oferecidos ao grupo alguns cenários, reproduções de situações reais vivenciadas nas escolas, para que em pequenos grupos os participantes refletissem sobre eles e sugerissem algum tipo de curso de ação.

O segundo encontro terminou com alguns delineamentos para um plano de ação do GR abrangendo as quatro DE que na verdade nunca se concretizou. Entretanto, é possível vislumbrar que apesar do conhecimento amealhado pelo grupo sobre autonomia e gestão democrática, o suposto plano não apontaria na direção do desenvolvimento prático dessas concepções, pois seu eixo norteador anunciado era a gestão pedagógica e de resultados, sem esclarecer quais seriam esses resultados e a quem eles serviriam. Por outro lado, aspectos como a autoformação, a avaliação e a organização do trabalho 
também foram contemplados, o que indicaria uma busca do grupo no sentido de construir sua própria formação.

Talvez a marca da formação no GR em 2013 tenha sido o desenvolvimento de uma atitude questionadora por parte de seus integrantes. Eles foram abandonando a perspectiva de que o grupo subsidiaria ações e passaram a questionar o próprio processo formativo e várias dimensões da gestão educacional.

No terceiro encontro, o grupo estabeleceu que muito deveria ser mudado nas práticas gestoras correntes para que se aprimorassem os processos de ensino e de aprendizagem nas escolas e que essas práticas, impregnadas de concepções gerencialistas e burocráticas, deveriam ser reconstruídas de acordo com a cultura de cada escola e comunidade, assim como com as novas demandas de nossa sociedade. Para os gestores essa mudança não parecia nada fácil, notadamente pelos enraizamentos de práticas gestoras tradicionais, que empoderavam o sistema educacional na figura do diretor de escola. Um dos possíveis caminhos apontados seria a elaboração participativa do Projeto Político Pedagógico em cada comunidade escolar.

O tema do quarto encontro formativo de 2013, como havia sido acordado no primeiro, foi o currículo. Chegou-se a um consenso de que um dos temas que afloraram durante o ano havia sido a questão da diversidade das culturas escolares. Essa diversidade seria um desafio às equipes gestoras e geraria a necessidade de adequações no currículo oficial da rede estadual. Surgiram questionamentos relacionados a como educadores identificavam e trabalhavam com as diferenças encontradas no espaço escolar, ignorandoas, silenciando sobre elas ou as reconhecendo. Eles entenderam a necessidade de cada escola identificar a sua cultura para poder buscar seus próprios caminhos. Também foi reconhecido que diferenças entre culturas geram conflitos, que por sua vez dão origem a dificuldades que são desafios às equipes gestoras. A importância de entender as culturas escolares residiria na sua influência nos diversos currículos ocultos, que por sua vez influenciavam e eram influenciados pelo currículo prescrito.

No bojo dessa discussão aparece novamente a valorização da autoformação no GR. Os gestores consideraram que essa discussão sobre cultura escolar e currículo seria um dos objetivos dos estudos a serem desenvolvidos pelo grupo no ano posterior, considerando a pertinência de estender esses estudos a todos os gestores das DE. Eles inclusive indicaram alguns livros e filmes que poderiam subsidiar esse trabalho. 
Quanto à avaliação do GR em 2013, vários aspectos foram levantados e discutidos pelo grupo. Primeiramente, os gestores colocaram que o GR tinha conseguido coordenar algumas ações de formação nas DE como queria a secretaria e que ele havia também promovido seus amadurecimentos profissionais. Foi afirmado também que estaria em curso um processo de aprofundamento teórico, de articulação entre teoria e prática, aspectos que constituiriam a identidade do GR. Essa articulação propiciaria o trabalho educativo de acordo com cada realidade escolar. Também foi levantado que o trabalho de cada equipe em suas DE suscitou discussões relativamente críticas em relação às políticas públicas oficiais. Por outro lado as discussões sobre autonomia e participação no GR estariam propiciando aprimoramento nos trabalhos dos Conselhos Escolares. Uma dificuldade que teria sido encontrada foi a concorrência com outras formações oferecidas pela própria SEE/SP.

\section{Análise e discussão da formação de gestores no GR}

A formação de gestores escolares no GR encerrou-se no final de 2013, sem quaisquer explicações por parte da CGEB sobre as razões pelas quais isso teria ocorrido, ou qual/ que tipo de formação poderia dar continuidade ou substituir o GR. Por outro lado, não tomamos conhecimento de nenhuma iniciativa e/ou manifestação por parte dos gestores participantes do Núcleo 02 , foco do nosso estudo, objetivando entender as razões do encerramento da formação ou de reivindicação de sua continuidade. Portanto, pareceunos que a descontinuidade e aparente desperdício de tempo e energia na formação são considerados como aspectos comuns nas formações oferecidas pela secretaria, tanto pela CGEB, como pelos educadores.

A análise dos dados levantados sobre essa formação indica que os percursos formativos dos gestores participantes do GR foram marcados por uma série de contradições. Houve no período inicial, nos encontros de 2011, uma grande expectativa por parte deles em relação às possibilidades de desenvolvimento de uma formação relativamente autônoma, participativa e, portanto, democrática. Por outro lado, eles também pareciam desejar que essa formação fosse organizada pela SEE/SP, principalmente no que se referia aos aportes teóricos necessários para a tematização das problemáticas que julgavam relevantes. O fato de que o Plano de Formação (SÃO PAULO, 2011) não oferecia esse tipo de direcionamento e que os formadores da secretaria estavam claramente despreparados para senão conduzir, organizar os trabalhos, 
criou um clima de insegurança e insatisfação entre os participantes, que perdurou durante os dois anos e meio da formação.

Essa evidência revela o quanto as concepções de autonomia e de participação (RISCAL, 2009; LIBÂNEO; OLIVEIRA; TOSCHI, 2009), que permearam toda a formação, estavam restritas a um plano apenas discursivo, isto é, esses conceitos, assim como a gestão democrática, da qual são pilares, se fazem presentes em muitas das reflexões empreendidas nas escolas e nas formações, mas ainda estão muito distantes de fomentarem práticas autônomas e participativas. Assim, podemos supor que se não estão presentes nas formações, suas ausências nas práticas educativas devem ser ainda mais significativas.

Cremos que esse quadro, no qual a gestão democrática baseada na autonomia e na participação não ultrapassa o plano das ideias, deve ter sua origem na dificuldade das escolas em desenvolver endogenamente e autonomamente suas próprias culturas participativas, para que elas ultrapassem o campo nominal da administração escolar e possibilitem práticas realmente democráticas:

Para que a «gestão participativa» não se resuma a uma mera técnica gestionária de motivação dos trabalhadores e de rentabilização do seu trabalho, torna-se necessário que ela esteja intimamente ligada ao desenvolvimento de «uma cultura de participação» na própria escola. Entendendo, neste caso, por «cultura de participação»o reconhecimento, por todos os membros da organização e pelos seus dirigentes, da participação como um valor essencial que deve orientar todas as suas práticas (BARROSO, 1995, P.16).

Entretanto, devemos admitir que essa ambiguidade patente entre discursos e práticas, que se refletiu e concretizou no GR, causadora de uma angústia praticamente constante, não paralisou os gestores, que demonstraram durante todas as etapas disposição tanto para contribuir como para receber contribuições no grupo, além de gerirem a organização dos encontros, ainda que muitas vezes expressassem a percepção de que a cada um deles reiniciavam seus estudos e reflexões da estaca zero, em função, principalmente, do vácuo da secretaria tanto no que se referia à organização como em relação a propostas formativas. 
Pensamos, dessa forma, que os gestores tiveram muita dificuldade em lidar com a pouca autonomia que lhes foi outorgada no início dos trabalhos do GR, porque ainda não vinham construindo essa autonomia em suas escolas e DE, por isso eles pareciam não se sentirem aptos a articular um trabalho formativo consistente independentemente da secretaria. Eles se esforçaram bastante nesse sentido, o que resultou em propostas que poderiam tê-los auxiliado na (re) construção de concepções e práticas e, sobretudo, na compreensão da importância do estudo e da reflexão no embasamento de suas ações nas escolas. Portanto, consideramos que os trabalhos no GR poderiam ter moderadamente propiciado algumas articulações entre a formação e práticas gestoras, ainda que de forma incipiente e pontual.

Esse aspecto deve ser visto com cuidado, uma vez que os gestores indicaram que durante a formação algumas influências reciprocas entre formação e práticas existiram, mas não há como afirmar quão significativas e/ou duradouras teriam sido essas influências, pois isso exigiria a continuidade da pesquisa para além da formação. O que se pode afirmar é que, com a pouca autonomia que lhes foi outorgada, os gestores, tentaram, no plano coletivo do grupo, tematizar alguns de seus problemas, dificuldades e práticas. Essas tematizações estavam, segundo os gestores, naquele momento, subsidiando suas ações nas escolas e nas DE.

Além disso, os gestores demonstraram ter noções sobre o que desejavam da formação como subsídios para suas práticas escolares. Eles pareciam ter clareza da premência do desenvolvimento de aspectos estruturais, atitudinais, tais como a necessidade de organização do trabalho coletivo na escola, principalmente da equipe gestora (PARO, 2005; LIBÂNEO; OLIVEIRA; TOSCHI, 2009). Eles foram específicos também sobre a importância de aportes teóricos e metodológicos para a elaboração de planos de ação nas áreas pedagógica e de gestão, conseguindo estabelecer a ligação entre currículo, gestão e ensino (GIMENO SACRISTÁN, 2013). Eles discutiram ainda suas concepções sobre as relações entre práticas e experiências formativas, explicitando a necessidade de articulação delas a partir das escolas e DE com o apoio da secretaria (CONTRERAS, 2002; IMBERNÓN, 2005; 2009).

Portanto, o que se pode afirmar em relação aos gestores participantes da formação no GR foco deste estudo é que a gestão democrática dos sistemas de ensino e das escolas, baseada na construção coletiva da autonomia e da participação ainda se restringe ao campo das ideias, que vêm sendo gradativamente disseminadas entre esses educadores. 
A formação no GR, apesar de ter sido perpassada por essas ideias, parece ter conseguido no máximo que os gestores tivessem a possibilidade de se apropriar delas de uma forma um pouco mais aprofundada, pois permitiu a criação de tempos e espaços para tematizações das práticas gestoras que bordearam essas ideias. A falta de clareza em relação a elas parece ter sido tanto da secretaria como dos gestores. O que nos parece ter faltado foi um genuíno apoio e consistência por parte da secretaria para que os gestores realmente conseguissem construir seus percursos formativos, o que a nosso ver, teria sido muito frutífero em relação as suas práticas nas escolas e DE.

\section{Algumas considerações}

Como já foi colocado, pelo que temos notícia, não houve continuidade dos trabalhos do grupo em 2014. Portanto, podemos concluir que apesar dos esforços empreendidos tanto pela SEE/SP: mobilização de formadores, organização dos grupos, elaboração de documentos, realização de encontros centrais; como pelos GR, nos núcleos e em cada DE e escola, a formação foi sendo esvaziada pela própria secretaria que aparentemente tentou experimentar um modelo formativo aberto, participativo com o objetivo de fomentar alguma autonomia dos participantes, mas, pelo que foi observado não teve fôlego, e mais provavelmente, estofo material, teórico e metodológico para leválo adiante.

Ficou implícita também nesse processo uma questão política, isto é, não nos parece que seria de interesse da secretaria fomentar núcleos de formação em todo o estado que de maneira autônoma e coletiva poderiam questionar e até se opor às políticas públicas por ela praticadas. Então, o gradativo esvaziamento dos GR não teria ocorrido somente por inépcia e/ou incompetência da secretaria, mas sim, conteria uma intencionalidade bem definida: desmobilizar grupos de gestores fortalecidos e regionalmente influentes.

Ao olharmos para trás, entendemos que tem sido válido o esforço investigativo objetivando compreender como foram sendo construídas as experiências formativas dos educadores participantes do GR. Essa validade referenda-se no aparente caráter inovador da formação, que propiciou uma meta análise e problematização sobre diversas formações oferecidas pela SEE/SP. Assim foi possível perceber o quanto a centralização da gestão da educação, que se reflete nessas formações, os têm influenciado, fazendo com que, mesmo havendo alguma autonomia, outorgada pelo próprio sistema, eles se mostrassem 
inseguros, perplexos e até manifestassem o desejo de receber uma formação pronta e acabada a ser imediatamente instrumentalizada em ações nas escolas e nas DE.

Segundo Toro (s/d, p. 02) "A democracia não é um partido, não é uma religião, não é uma ciência. A democracia é uma forma de ver o mundo: é uma cosmovisão". Ao concordarmos com o autor, devemos admitir que muito ainda há que ser feito para que as práticas educativas sejam mais democráticas em nossas escolas e que esse processo deve ser desencadeado por formações baseadas nas escolas, com o apoio dos sistemas de ensino, isto é, os sistemas deveriam criar condições para o desenvolvimento da autonomia, da participação nas escolas, e, assim, da democracia entre os educadores. sejam eles professores e/ou gestores.

Agradecimentos ao CNPq pelo apoio parcial.

\section{Notas}

${ }^{1}$ A CENP - Coordenadoria de Ensino e Normas Pedagógicas, órgão responsável pelos GR, foi substituída em 2012 por outro órgão, a CEGB - Coordenadoria de Gestão da Educação Básica, no processo de reestruturação da SEE/SP ocorrida naquele ano. A CEGB passou assim a gerir os GR.

\section{Referências}

AFONSO, A. J. Escola pública, gerencialismo e accountability. Página da educação, Porto, n.12, p.01-2, ago.-set. 2003. Disponível em: http://www.apagina.pt. Acesso em 07 jul. 2015.

BARROSO, J. O estudo da escola. Porto: Porto Editores, 1996.

Para o desenvolvimento de uma cultura de participação na escola. Lisboa:

Instituto de Inovação Educacional, 1995. Disponível em:

http://www.crmariocovas.sp.gov.br. Acesso em: 18 jun. 2015.

BOGDAN, R. C.; BIKLEN, S. K. Investigação qualitativa em educação: uma introdução à teoria e aos métodos. 9.ed. Porto: Porto Editores, 2010.

BRASIL. Lei Federal n. 9394/1996. Brasília: Ministério da Educação, 1996. Plano Nacional de Educação. Conferência Nacional de Educação: Documento

- Referência/Fórum Nacional de Educação. Brasília: Ministério da Educação, 2014.

CONTRERAS, J. A autonomia de professores. São Paulo: Cortez, 2002.

GIL, A. C. Como elaborar projetos de pesquisa. 4.ed. São Paulo: Atlas, 2002.

GIMENO SACRISTÁN, J. (Org.) Saberes e incertezas sobre o currículo. Porto Alegre: Penso, 2013. 
IMBERNÓN, F. Formação docente e profissional. São Paulo: Cortez, 2005.

Formação permanente do professorado: Novas tendências. São Paulo: Cortez, 2009.

LIBÂNEO, J.C.; OLIVEIRA, J. F.; TOSCHI, M. S. Educação escolar: políticas, estrutura e organização. 7.ed. São Paulo: Cortez, 2009.

MARQUES, L. R. Democracia radical e democracia participativa: contribuições teóricas à análise da democracia na educação. Educação e Sociedade, v. 29, n. 102, jan.abr., p. 55-78, 2008.

PARO, V. H. Gestão democrática da escola pública. 3.ed. São Paulo: Ática, 2005

PIMENTA, S. G. Pesquisa-ação-colaborativa: construindo seu significado a partir de experiências com a formação docente. Educação e Pesquisa, v. 31, n.03, set./dez., p. 521-539, 2005.

SÃO PAULO. Plano de formação continuada de professores e gestores: $2^{\circ}$ semestre de 2011 (2011). Diário Oficial do Estado de São Paulo - 11.07.2011. São Paulo:

Coordenadoria de Ensino e Normas Pedagógicas/ Secretaria da Educação, 2011.

Plano de formação continuada de gestores: 2012. Secretaria da Educação Circulação Interna. São Paulo: Coordenadoria de Gestão da Educação Básica/ Secretaria da Educação, 2012.

RISCAL, S. A. Gestão democrática no cotidiano escolar. São Carlos: EDUFSCar, 2009.

TORO, J.B. Educacion para la democracia. Bogotá: CIVICUS/Funredes. s/d.

Disponível em

http://funredes.org/funredes/html/castellano/publicaciones/educdemo.html. Acesso em

26 out. 2015. 